\title{
Postprandial expression of growth-related genes in Atlantic salmon (Salmo salar L.) juveniles fasted for 1 week and fed a single meal to satiation
}

\author{
Luísa M. P. Valente ${ }^{1 *}$, Neil I. Bower ${ }^{2}$ and Ian A. Johnston ${ }^{2}$ \\ ${ }^{1}$ CIMAR/CIIMAR - Centro Interdisciplinar de Investigação Marinha e Ambiental and ICBAS - Instituto de Ciências \\ Biomédicas de Abel Salazar, Universidade de Porto, Rua dos Bragas, 289, 4050-123 Porto, Portugal \\ ${ }^{2}$ Scottish Oceans Institute, School of Biology, University of St Andrews, St Andrews KY16 8LB, UK \\ (Submitted 21 September 2011 - Final revision received 2 December 2011 - Accepted 23 December 2011 - First published online 2 April 2012)
}

\begin{abstract}
We investigated postprandial changes in transcript abundance following a single satiating meal in juvenile Atlantic salmon (Salmo salar L.) (about $70 \mathrm{~g}$ body mass) following fasting for 1 week at $12^{\circ} \mathrm{C}$. The expression of twenty-three growth-related genes was determined in fast myotomal muscle using quantitative real-time PCR at the following postprandial time points: $-12,0,1,3,6,12,24,48$ and $96 \mathrm{~h}$. The gut was fullest $1-6 \mathrm{~h}$ after feeding and emptied within $48-96 \mathrm{~h}$. IGF-I, MyoD1c, MRF4 and myf5 transcripts were sharply up-regulated within $1 \mathrm{~h}$ of refeeding and are promising candidate genes involved in a fast-response signalling system that regulates fish myotomal muscle growth. These genes clustered together with $M y o D 1 b$ and suggest a coordinated regulation to favour resumption of myogenesis as an early response to feeding. Insulin-like growth factor (IGF)-II and the ubiquitin ligase MAFbx/atrogin-1 were initially down-regulated but restored to initial values after $12 \mathrm{~h}$. It is also suggested that local production of IGF-I within the muscle might suppress catabolic pathways depressing MAFbx/atrogin-1.
\end{abstract}

Key words: Salmo salar L.: Myogenesis: Refeeding and fasting: Nutrient availability: Insulin-like growth factor system

The natural life cycle of many fish species often includes long periods of low winter temperatures and restricted feeding opportunities or prey availability that lead to a depletion of energy reserves and a reduction in growth rate ${ }^{(1)}$. The restoration of adequate nutrition or favourable environmental conditions results in rapid weight gain and compensatory growth relative to continuously fed controls. Compensatory growth occurs at various stages in salmonid fish and is an important adaptation that allows fish to remain on target in a fluctuating and unpredictable environment ${ }^{(2-5)}$. From a practical point of view, the compensatory strategy is of great interest to the aquaculture industry because feeding programmes can be designed to improve food conversion and growth rates, thereby minimising production costs ${ }^{(1)}$.

Periods of nutrient restriction are associated with changes in metabolism to provide cellular energy via catabolic processes $^{(3)}$. In carnivorous fish, nutrient restriction enhances the release of amino acids from muscle fibres which are used by hepatocytes as the main gluconeogenic precursors ${ }^{(6)}$. During refeeding and compensatory growth an accelerated turnover takes place resulting in an increased protein synthesis: degradation ratio ${ }^{(3,7)}$. In salmon, the main mechanism underlying compensatory growth after a nutrient-restriction period is an increase of feed intake rates ${ }^{(2)}$. Food contains ligands for retinoic acid receptors, PPAR, vitamin D receptors and other nuclear transcription factor receptors and can directly affect signal transduction pathways ${ }^{(8,9)}$. Branchedchain amino acids, particularly leucine, have a major role in stimulating protein synthesis ${ }^{(10)}$. These phenomena seem to be the result of endocrine alterations, although in most species it is difficult to detect differences in the endocrine status between animals undergoing compensatory growth and control animals ${ }^{(11)}$. In fish, recent molecular tools enable us to gain deeper insight into how growth responses are regulated by dietary factors ${ }^{(12,13)}$. In Atlantic salmon ${ }^{(14)}$ and rainbow trout $^{(15)}$ a genomic approach was used to identify nutritionally regulated genes involved in muscle growth and revealed a complex response. The principal groups of up-regulated transcripts post-refeeding were genes involved in transcription, ribosomal biogenesis, translation, chaperone activity,

Abbreviations: IGF, insulin-like growth factor; IGFBP, insulin-like growth factor binding protein; MRF, muscle regulatory factor; MTor, mammalian target of rapamycin; MuRF1, muscle RING finger protein 1; PI3K, phosphoinositide-3-kinase; QPCR, quantitative real-time PCR. 
ATP production, cell division and muscle remodelling. These genes possibly play a role in the stimulation of myogenesis during the transition from a catabolic to anabolic state in skeletal muscle

Several in vivo and in vitro studies evaluated the impact of feeding protocols on muscle growth. Using a candidate gene approach, it was observed that switching onto fast growth induced by a fasting-refeeding schedule involves the local up-regulation of several components of the insulin-like growth factor (IGF) system, a major hormone axis regulating the cellular dynamics of muscle growth ${ }^{(16-19)}$. The role of plasma IGF-I during compensatory growth is not clear and must be explained in connection with changes of its binding proteins, which act on the phosphoinositide-3-kinase/Akt/ mammalian-target-of-rapamycin (PI3K/Akt/mTOR) pathway $^{(20,21)}$. The autocrine IGF-II transcription required for skeletal myocyte differentiation is regulated by mTOR and the availability of amino acids ${ }^{(22,23)}$. Thus the mTOR-IGF axis provides a molecular link between nutritional levels and protein synthesis leading to muscle fibre hypertrophy. In salmonids, fasting decreased the expression and plasma levels of IGF, and up-regulated IGF-I binding, whereas the plasma level of growth hormone was shown to increase ${ }^{(24,25)}$. Switching to fast growth in Atlantic salmon muscle involved the upregulation of IGF-I, IGF binding protein (IGFBP)-5.2 and IGFBP-4 ${ }^{(19)}$, whereas $1 \mathrm{~d}$ of refeeding completely restored plasma growth hormone levels in rainbow trout ${ }^{(24)}$. IGF-I induced the activation of the $\mathrm{PI} 3 \mathrm{~K} / \mathrm{Akt}$ pathway, which causes an increase in protein translation via activation of p7056K and inhibition of 4E-BP (also known as PHAS-1) ${ }^{(24)}$. In cell lines, it was recently shown that in addition to its hypertrophic effects, Akt can dominantly inhibit induction of the atrophy genes the muscle-specific E3 ubiquitin ligases, MuRF1 (muscle RING finger protein 1) and MAFbx/atrogin-1 (muscle atrophy $\mathrm{F}$ box), by phosphorylating and thereby inhibiting the function of the forkhead box O (FOXO) family of transcription factors $(26,27)$

The genetic networks mobilised in muscle following recovery from fasting are likely to be dependent on nutrient availability. The experimental protocols employed to investigate compensatory growth often involve prolonged fasting followed by continuous refeeding with transcript abundance monitored over several days or weeks ${ }^{(14,17,28,29)}$. In contrast, a single satiating meal design allows the evolution and decay of transcriptional responses to nutrient input to be studied with relatively high temporal resolution. Using this approach the aim of the present study on Atlantic salmon was to investigate the transcript abundance of muscle growth-related genes to changes in nutrient supply. The expression of genes involved in myogenesis (muscle regulatory factors (MRF) and paired box protein 7 ( $\operatorname{Pax} 7)$ ), growth signalling (the IGF system), myofibrillar protein degradation and synthesis pathways (the PI3K/AKT/mTOR pathway and the muscle-specific E3 ubiquitin ligases) and metabolic genes $(\mathrm{Creb} A)$ shown to be critical modulators of fish myotomal muscle growth were analysed using quantitative real-time PCR (qPCR)

\section{Materials and methods}

\section{Experimental conditions and sampling}

All experiments were approved by the Animal Welfare Committee of the University of St Andrews and fish were humanely killed following Schedule 1 of the Animals (Scientific Procedures) Act 1986 (Home Office Code of Practice, H. M Stationery Office: London, January 1997).

Two homogeneous groups of Atlantic salmon (Salmo salar $\mathrm{L}$.) juveniles (average body weight $70 \mathrm{~g}$ ) were reared in duplicate tanks (500 litres; thirty fish per tank). Each tank was supplied with fresh water with an average water temperature of $12^{\circ} \mathrm{C}$ and dissolved oxygen $>80 \%$. Fish were exposed to an artificial photoperiod of $12 \mathrm{~h}$ light- $12 \mathrm{~h}$ dark $(08.00$ to 20.00 hours) and provided a commercial salmon feed (EWOS Innovation) during 3 weeks ( $1.5 \%$ body weight). Fish were then fasted for 1 week, and fed a single meal distributed to all fish to visual satiation.

Sampling of fish occurred at -12 and $0 \mathrm{~h}$ (before the meal), and at 1, 3, 6, 12, 24, 48 and $96 \mathrm{~h}$ (following the single meal), with seven fish sampled at each time point and individual mass and fork lengths measured. The intestine and stomach content was determined for each fish and photographs were taken. Fast muscle was then dissected from the dorsal myotome and snap-frozen in liquid $\mathrm{N}_{2}$. Samples were kept at $-80^{\circ} \mathrm{C}$ until analysed.

\section{RNA extraction and CDNA synthesis}

Total RNA was extracted by the addition of $100 \mathrm{mg}$ of salmon muscle to Lysing matrix D (Qbiogene) with $1 \mathrm{ml}$ TRI reagent (Sigma) and homogenised for $40 \mathrm{~s}$ using a Fast Prep instrument (Qbiogene). Total RNA was quantified based on absorbance at $260 \mathrm{~nm}$ using a NanoDrop spectrophotometer (ThermoFisher Scientific) and its integrity was confirmed by agarose gel electrophoresis on a $1.2 \%$ gel $(\mathrm{w} / \mathrm{v})$ after 3-5 min denaturation at $65^{\circ} \mathrm{C}$. Genomic DNA contamination was removed and first-strand cDNA was synthesised from $1 \mu \mathrm{g}$ total RNA with the QuantiTect reverse transcription kit (Qiagen) following the manufacturer's instructions.

\section{Quantitative real-time $P C R$}

The following procedures were performed in order to comply with the Minimum Information for Publication of Quantitative Real-Time PCR experiments MIQE guidelines ${ }^{(30)}$

Several muscle growth-related genes (Table 1) (IGF-I, IGFII, IGF-IRa, IGF-IRb, IFG-IIR, IGFBP-2·1, IGFBP-4, IGFBP-5·1, IGFBP-5.2, IGFBP-6, IGFBP-rP1, Myogenin, MyoD1a, MyoD1b, MyoD1c, myf5 (myogenic factor 5), MRF4 (also known as myogenic factor 6; $m y f($ ), the E3 ubiquitin ligases MuRF1 and $M A F b x /$ atrogin-1, fibroblast growth factor 2 (FGF2), CrebA, MEF2A, Pax 7 and five reference genes, HPRT1 (hypoxanthine phosphoribosyltransferase 1), elongation factor $1-\alpha(E F 1-\alpha)$, 60 S ribosomal protein L13 (rpl13), 40S ribosomal protein S29 (rps29), beta-actin and $R N A$ polymerase II) were selected, and primers were designed to have a melting temperature $\left(\mathrm{T}_{\mathrm{m}}\right)$ of $60^{\circ} \mathrm{C}$ as previously 
Table 1. Summary of parameters for quantitative real-time PCR (qPCR)

\begin{tabular}{|c|c|c|c|c|c|}
\hline Gene & Primer $5^{\prime}-3^{\prime}$ & Product size (bp) & Temperature $\left({ }^{\circ} \mathrm{C}\right)$ & $E(\%)$ & Accession number \\
\hline$I G F-I$ & $\begin{array}{l}\text { f: CCTGTTCGCTAAATCTCACTTC } \\
\text { r: TACAGCACATCGCACTCTTGA }\end{array}$ & 226 & $81 \cdot 8$ & 102 & EF432852 \\
\hline IGF-II & $\begin{array}{l}\text { f: GGAAAACACAAGAATGAAGGTCAA } \\
\text { r: CCACCAGCTCTCCTCCACATA }\end{array}$ & 127 & $82 \cdot 8$ & 100 & EF432854 \\
\hline IGF-IRa & $\begin{array}{l}\text { f: GGGGCTCTCCTTCTGTCCTA } \\
\text { r: AGAGATAGACGACGCCTCCTA }\end{array}$ & 175 & $86 \cdot 0$ & $97 \cdot 2$ & EU861008 \\
\hline$I G F-I R b$ & $\begin{array}{l}\text { f: CCTAAATCTGTAGGAGACCTGGAG } \\
\text { r: GGTTAGCCACGCCAAATAGATCC }\end{array}$ & 138 & 83.5 & 100 & EU861006 \\
\hline IGF-IIR & $\begin{array}{l}\text { f: CTTCATCCACGCTCAGCAG } \\
\text { r: ACCCTGGGCCGTGTCTAC }\end{array}$ & 168 & $84 \cdot 4$ & $98 \cdot 95$ & CX325971 \\
\hline IGFBP-2.1 & $\begin{array}{l}\text { f: CGGTGAGGAAGGCCACTAAGG } \\
\text { r: ATATCACAGTTGGGGATGT }\end{array}$ & 249 & $85 \cdot 5$ & 95 & EF432858 \\
\hline$I G F B P-4$ & $\begin{array}{l}\text { f: ACTTCCATGCCAAGCAGTGC } \\
\text { r: GGTCCCATCCTCACTCTCTC }\end{array}$ & 164 & $87 \cdot 6$ & $104 \cdot 2$ & EU861007 \\
\hline IGFBP-5.1 & $\begin{array}{l}\text { f: ATCACGGAGGACCAACTGC } \\
\text { r: TGCTTGTCAATGGGTAGTGG }\end{array}$ & 169 & $87 \cdot 1$ & $107 \cdot 1$ & EF432862 \\
\hline IGFBP-5.2 & $\begin{array}{l}\text { f: TTCTCCAGAGGAAGCTATGTTAG } \\
\text { r: TCAAGGCTGCTGACAGAGTG }\end{array}$ & 170 & $86 \cdot 6$ & $112 \cdot 6$ & EU861009 \\
\hline IGFBP-6 & $\begin{array}{l}\text { f: GCTGCGTGCCTCTTCCTCA } \\
\text { r: TTACGGCAGGGTGCCTTTTC }\end{array}$ & 159 & $86 \cdot 5$ & $87 \cdot 6$ & EF432864 \\
\hline IGFBP-rP1 & $\begin{array}{l}\text { f: GAAGTGTGTGGCTCCGATG } \\
\text { r: GTTTTCCGCTGGTGACCTTCT }\end{array}$ & 249 & $85 \cdot 0$ & $104 \cdot 5$ & EF432866 \\
\hline Myogenin & $\begin{array}{l}\text { f: GTGGAGATCCTGAGGAGTGC } \\
\text { r: CTCACTCGACGACGAGACC }\end{array}$ & 146 & $85 \cdot 3$ & $101 \cdot 1$ & DQ294029 \\
\hline CrebA & $\begin{array}{l}\text { f: GGAGTCTGTTTCGCTAAGTCG } \\
\text { r: CGTAGGACCGCTGGATGT }\end{array}$ & 168 & $85 \cdot 5$ & $100 \cdot 9$ & CU073780 \\
\hline FGF2 & $\begin{array}{l}\text { f: ATAAGCTTCAACTCCAGGCGACC } \\
\text { r: AGCATTCATCTGTTGTCCGTCTC }\end{array}$ & 230 & $82 \cdot 3$ & 91 & GE794494 \\
\hline MAFbx/atrogin-1 & $\begin{array}{l}\text { f: AAAGGAAGCACTAAAGAGCGTC } \\
\text { r: CTGGGACTTGGCAATGAGC }\end{array}$ & 137 & $85 \cdot 0$ & $102 \cdot 9$ & DN165813 \\
\hline$M E F 2 A$ & $\begin{array}{l}\text { f: ACCGGCTACAACACCGAGTA } \\
\text { r: CCTGGCCCAGTTGATGTT }\end{array}$ & 121 & $84 \cdot 8$ & 102 & DY713536 \\
\hline MuRF1 & $\begin{array}{l}\text { f: AGGCGGGATCAGAGCTAAC } \\
\text { r: CGACCATTCCAAAGTCCATC }\end{array}$ & 229 & $87 \cdot 5$ & $100 \cdot 88$ & DN165465 \\
\hline myf5 & $\begin{array}{l}\text { f: CGCCATCCAGTACATCGAG } \\
\text { r: TCTCCAGAGCTCACATTCTTAGTAT }\end{array}$ & 213 & $85 \cdot 5$ & $100 \cdot 1$ & DQ452070 \\
\hline MyoD1a & $\begin{array}{l}\text { f: CCAAATAGTTCCAGACGCAAG } \\
\text { r: ACAGCGGGACAGGCAGAGG }\end{array}$ & 104 & $81 \cdot 0$ & $109 \cdot 3$ & AJ557148 \\
\hline MyoD1b & $\begin{array}{l}\text { f: CGGCGAGAACTACTACCCTATGT } \\
\text { r: GGCACCAGCATTTGGAGTTTC }\end{array}$ & 172 & $83 \cdot 0$ & $101 \cdot 25$ & AJ557150 \\
\hline MyoD1c & $\begin{array}{l}\text { f: CCCTTCGCTGGAGCACTACAACG } \\
\text { r: GCTTCTGGCATCAGCATTTGGAG }\end{array}$ & 163 & $84 \cdot 5$ & $104 \cdot 4$ & DQ317527 \\
\hline Pax7 & $\begin{array}{l}\text { f: GGAACAGTGCCTCGAATGATG } \\
\text { r: GGTCCTGCATATTGTCCTTCCA }\end{array}$ & 85 & $84 \cdot 0$ & $99 \cdot 15$ & NM_001123695 \\
\hline MRF4 & $\begin{array}{l}\text { f: CAATGACGAATCAAGAGAGAAGGC } \\
\text { r: GACAGGCGAAGAAGGCTGGTGG }\end{array}$ & 64 & $80 \cdot 0$ & $100 \cdot 9$ & DQ4799521 \\
\hline$E F 1-\alpha$ & $\begin{array}{l}\text { f: GAATCGGCTATGCCTGGTGAC } \\
\text { r: GGATGATGACCTGAGCGGTG }\end{array}$ & 141 & $85 \cdot 3$ & $102 \cdot 0$ & BG933853 \\
\hline Rp/13 & $\begin{array}{l}\text { f: CGCTCCAAGCTCATCCTCTTCCC } \\
\text { r: CCATCTTGAGTTCCTCCTCAGTGC }\end{array}$ & 79 & 84.3 & $94 \cdot 6$ & ВТ043698 \\
\hline Rps29 & $\begin{array}{l}\text { f: GGGTCATCAGCAGCTCTATTGG } \\
\text { r: AGTCCAGCTTAACAAAGCCGATG }\end{array}$ & 167 & $84 \cdot 5$ & $99 \cdot 5$ & NM_001139600 \\
\hline beta-actin & $\begin{array}{l}\text { f: TGACCCAGATCATGTTTGAGACC } \\
\text { r: CTCGTAGATGGGTACTGTGTGGG }\end{array}$ & 146 & $85 \cdot 5$ & $102 \cdot 0$ & G933897 \\
\hline RNA pol II & $\begin{array}{l}\text { f: CCAATACATGACCAAATATGAAAGG } \\
\text { r: ATGATGATGGGGATCTTCCTGC }\end{array}$ & 157 & $84 \cdot 8$ & $113 \cdot 0$ & BG936649 \\
\hline HPRT1 & $\begin{array}{l}\text { f: CCGCCTCAAGAGCTACTGTAAT } \\
\text { r: GTCTGGAACCTCAAACCCTATG }\end{array}$ & 255 & $81 \cdot 7$ & $99 \cdot 0$ & EG866745 \\
\hline
\end{tabular}

E, PCR efficiency; f, forward; r, reverse; IGF-I, insulin-like growth factor I; IGF-II, insulin-like growth factor II; IGF-IRa, insulin-like growth factor I receptor a; IGF-IRb, insulin-like growth factor I receptor b; IGF-IIR, insulin-like growth factor II receptor; IGFBP-2.1, insulin-like growth factor binding protein 2 paralogue 1; IGFBP-4, insulin-like growth factor binding protein 4; IGFBP-5.1, insulin-like growth factor binding protein 5 paralogue 1; IGFBP-5.2, insulin-like growth factor binding protein 2 paralogue 2; IGFBP-6, insulin-like growth factor binding protein 6; IGFBP-rP1, insulin-like growth factor binding protein-related protein 1; CrebA, cyclic AMP response element binding protein; FGF2, fibroblast growth factor 2; MAFbx, muscle atrophy F box; MEF2A, myocyte enhancer factor 2A; MuRF1, muscle RING finger protein 1; myf5, myogenic factor 5; MyoD1a, myoblast determination factor 1a; MyoD1b, myoblast determination factor $1 \mathrm{~b}$; MyoD1c, myoblast determination factor 1c; Pax7, paired box protein 7; MRF4, myogenic factor 6; EF1- $\alpha$, elongation factor 1- $\alpha$; Rp/13, 60S ribosomal protein L13; Rps29, 40S ribosomal protein S29; RNA pol II, RNA polymerase II; HPRT1, hypoxanthine phosphoribosyltransferase 1. 
reported by Bower et al. ${ }^{(14,19)}$. Quantification of gene expression was performed by qPCR using a Stratagene MX3005P QPCR system (Stratagene) with SYBR Green chemistry (Brilliant II SYBR green, Stratagene). The cDNA were diluted $80 \times$ before using them as templates for the qPCR reactions. Each qPCR reaction mixture contained $7 \cdot 5 \mu \mathrm{l}$ $2 \times$ Brilliant II SYBR green master mix, $6 \mu \mathrm{l}$ cDNA (80-fold dilution), $500 \mathrm{~nm}$ each primer and RNAse-free water to a final volume of $15 \mu \mathrm{l}$. Amplification was performed in duplicate in ninety-six-well plates with the following thermal cycling conditions: initial activation $95^{\circ} \mathrm{C}$ for $10 \mathrm{~min}$, followed by forty cycles of $15 \mathrm{~s}$ at $95^{\circ} \mathrm{C}, 30 \mathrm{~s}$ at $60^{\circ} \mathrm{C}$ and $30 \mathrm{~s}$ at $72^{\circ} \mathrm{C}$. Dissociation analysis of the PCR products was performed by running a gradient from 60 to $95^{\circ} \mathrm{C}$ to confirm the presence of a single PCR product. The PCR amplification efficiency of each primer pair was calculated using LinregPCR 2009 (http://LinRegPCR.HFRC.nl) ${ }^{(31)}$.

\section{Data analysis}

Evaluation of expression stability of several potential housekeeping genes including elongation factor $1-\alpha$ (EF1- $\alpha$ ), 605 ribosomal protein L13, rpl13, $40 \mathrm{~S}$ ribosomal protein S13 and S29 (rps13 and rps29), beta-actin and RNA polymerase II was done using the statistical application called geNorm (http://medgen.ugent.be/ jvdesomp/genorm/ $)^{(32)}$. Analysis revealed both rpl13 and RNA polymerase II as the most stable genes in this experiment. Hence, the reference gene rpl13 was used for normalisation of qPCR data and QGene was used for normalisation and calculation of relative expression data ${ }^{(33)}$

All data were tested for normality and homogeneity of variances by Kolmogorov-Smirnov and Bartlett tests, and then submitted to a one-way ANOVA using STATISTICA software (version 10; StatSoft, Inc.). When the data did not meet the normality and/or equal variance requirements, a KruskalWallis one-way ANOVA on ranks was performed instead. When these tests showed significance, individual means were compared using Tukey's honestly significant difference test or Dunn's test. Correlation of gene expression was analysed by the Spearman rank order correlation test. Hierarchical clustering was performed using Cluster3 software ${ }^{(34)}$.

\section{Results}

Fish mass and length ranged between $90-117 \mathrm{~g}$ and $20-$ $23 \mathrm{~cm}$, respectively, and were similar among sampling points $(P<0.05)$. The gut content of the salmon increased significantly $1 \mathrm{~h}$ after distributing the meal and remained high for $6 \mathrm{~h}$ (Fig. 1). These results confirm that all sampled fish had ingested food, and the intestine was fully evacuated between 48 and $96 \mathrm{~h}$ after the meal.

An up-regulation of several components of the IGF system was observed immediately after the meal. IGF-I transcripts increased significantly $1 \mathrm{~h}$ after the single meal $(P<0.05)$, decreasing thereafter (Fig. 2). Expression of $I G F-I I$ was significantly reduced in response to feeding $(P<0.05)$ with

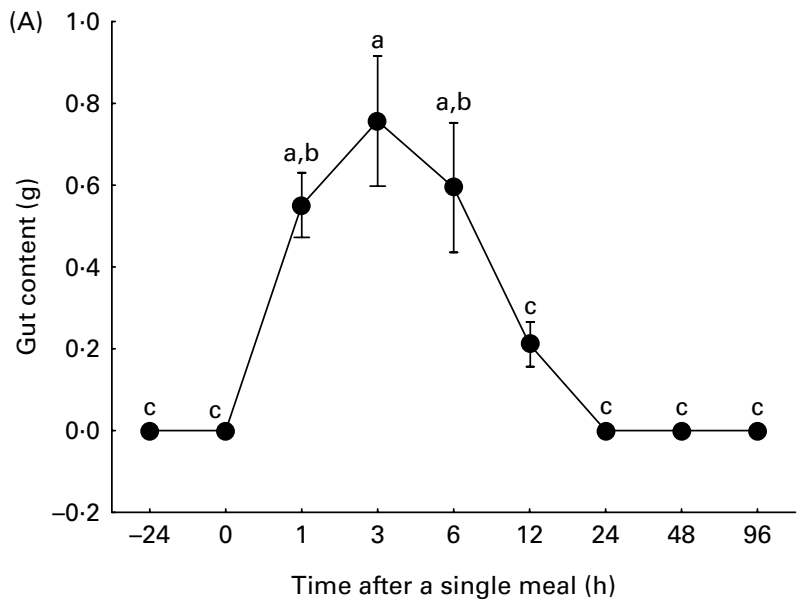

(B)
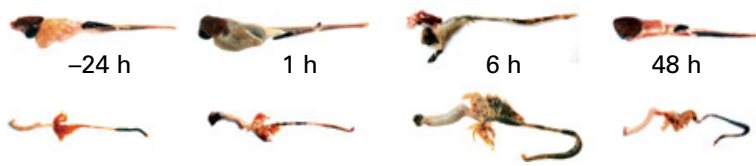

Fig. 1. (A) Gut content ( $\mathrm{g}$ ) of fish sampled before (T-24 and T0) and severa hours (T1-T96) after feeding a single meal to satiation. Values are means (seven fish per sample), with their standard errors represented by vertical bars. ${ }^{a, b, c}$ Mean values with unlike letters were significantly different $(P<0.05)$. (B) Photographs of gut and intestine, which were dissected to ensure the presence of food in the stomach and to follow their fullness during the course of the single meal experiment. Scale bar $=2 \mathrm{~cm}$.

significant down-regulation observed at 3 and $6 \mathrm{~h}$ after the single meal, returning to initial values after $12 \mathrm{~h}$

Expression levels of $I G F-I R b$ (Fig. 2) and IGF-IIR did not vary significantly in response to feeding ( $P>0.05)$, but IGF-IRa was minimal $12 \mathrm{~h}$ after the single meal. Several IGFBP were detected in fast muscle of Atlantic salmon (Fig. 3). IGFBP-related protein 1 (IGFBP-rP1), IFGBP-2.1 and IGFBP-5.2 expression did not vary significantly with the single meal. IGFBP-4 and IGFBP-5.1 had increased expression $1 \mathrm{~h}$ after the meal administration, but then decreased. IGFBP- 6 expression decreased $12 \mathrm{~h}$ after the meal, reaching maximal expression levels $48 \mathrm{~h}$ postprandially. $I G F B P-6$ was significantly correlated with $I G F-I I(P<0 \cdot 05)$. A positive correlation was found between IGF-I, IGFBP-rP1 and IGFBP-4 expression.

Expression of MRF revealed that MRF4 and myf5 expression were significantly correlated with the gut content of the fish $(P<0.05)$. These two genes were up-regulated until $3 \mathrm{~h}$ after the single meal, returning to initial values $6 \mathrm{~h}$ after feeding (Fig. 4), and their expression clustered together when compared with other genes (Fig. 5). The three paralogues of MyoD1 responded differently to the meal distribution. MyoD1a showed no variation following the meal, whereas $M y o D 1 b$ and MyoD1c peaked $1 \mathrm{~h}$ after feeding a single meal, although without statistical significance in the case of $M y o D 1 b$. MyoD1c mRNA expression correlated with gut content $(P<0.05)$ and clustered together with $I G F-I$ (Fig. 5). Myogenin expression was not significantly affected by feeding, although a slight decrease was observed after feeding.

The ubiquitin ligase MAFbx/atrogin-1 mRNA levels were significantly down-regulated until $12 \mathrm{~h}$ after feeding, returning 
(A)

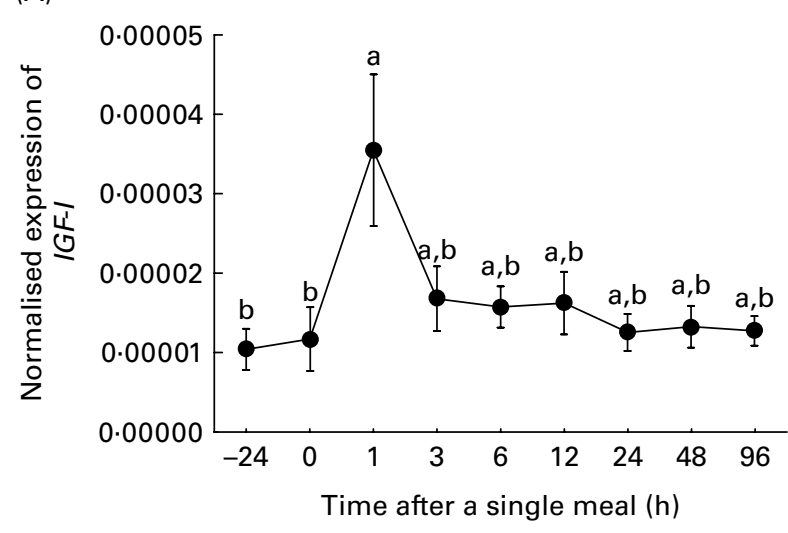

(C)
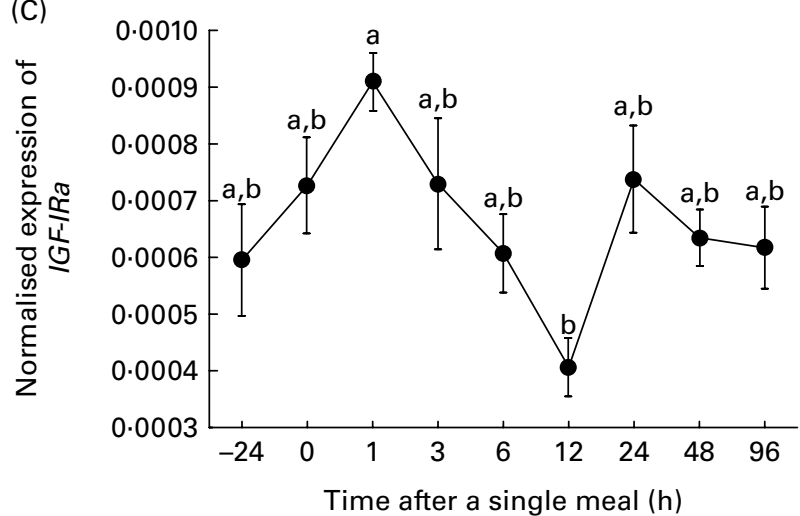

(B)

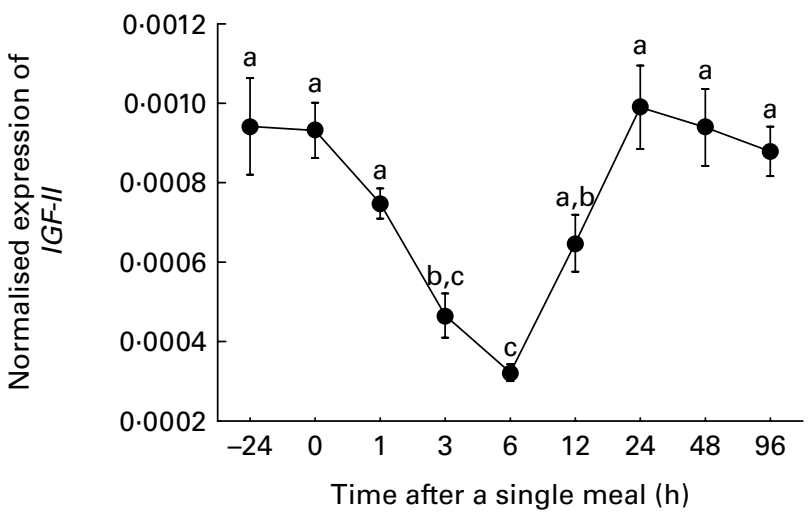

(D)

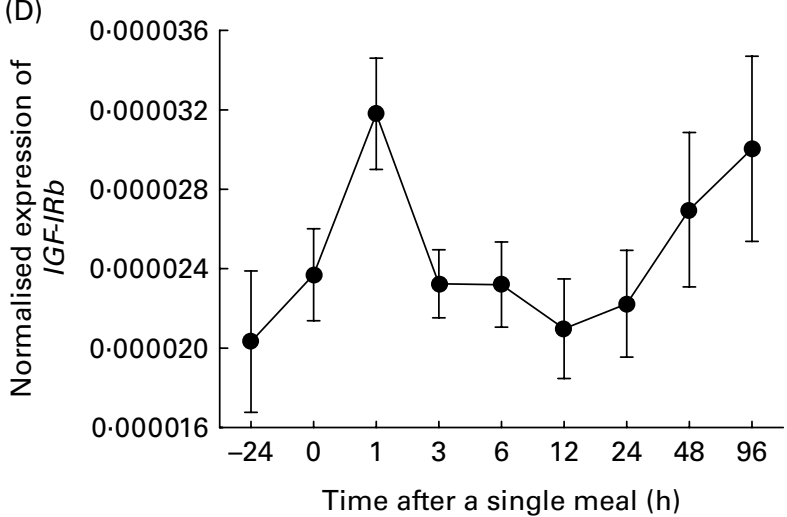

Fig. 2. Normalised expression of the insulin-like growth factor (IGF) system genes (IGF-I (A), IGF-II (B), IGF-IRa (C) and IGF-Irb (D)) in the fast myotomal muscle at different times postprandially. Values are means (seven fish per sample), with their standard errors represented by vertical bars. ${ }^{a, b, c}$ Mean values with unlike letters were significantly different $(P<0.05)$.

to levels observed in fasted fish by $24 \mathrm{~h}$ (Fig. 4). MuRF1 expression was initially up-regulated at $1 \mathrm{~h}$, before being down-regulated at 3 and $12 \mathrm{~h}$ postprandially. MAFbx/atrogin1 expression was positively correlated ( $R$ 0.66) with IGF-II. FGF2, CrebA and Pax7 expression was not significantly affected by the single meal distribution.

\section{Discussion}

Nutrient availability is amongst the most important environmental variable altering muscle growth. The genetic network that is mobilised in the stimulation of myogenesis during the transition from a catabolic to anabolic state in skeletal muscle has not been exhaustively described, but seems to be a nutrient-sensing pathway ${ }^{(12,13,15,35)}$. The present study was designed to explore the postprandial regulation of growth-related genes shortly after feeding a single meal.

The effects of fasting and subsequent continuous refeeding protocols following transcript abundance over time have been studied in several fish species such as Atlantic salmon ${ }^{(14,36)}$, rainbow trout ${ }^{(17,25)}$, Atlantic halibut ${ }^{(29)}$, sea bass ${ }^{(28)}$ and seabream $^{(37)}$. However, the only study describing early transcriptional changes during the postprandial period was recently performed in zebrafish ${ }^{(38)}$. The present results indicated that a single meal affects the expression of several growth-related genes in Atlantic salmon juveniles shortly after ingestion, confirming data in zebrafish ${ }^{(38)}$. A 3.5-fold increase of $I G F-I$ mRNA expression was observed $1 \mathrm{~h}$ after refeeding, indicating a fast response to nutrient availability. An increased expression of $I G F-I$ in fast skeletal muscle was registered 3-4 d after refeeding in Atlantic salmon ${ }^{(19)}$ and rainbow trout ${ }^{(17)}$, and after 1 week in sea bass ${ }^{(28)}$, although no earlier point was analysed. Duan, Plisetskaya ${ }^{(36)}$ also reported a significant increase in hepatic IGF-I mRNA levels in salmon after refeeding, suggesting an endocrine/autocrine/paracrine growth stimulation of myotomal muscle induced by food intake. In myogenic cell culture, Atlantic salmon IGF-I mRNA levels increase in response to IGF and amino acid stimulation. Seiliez et al. ${ }^{(21)}$ showed that in rainbow trout insulin levels peak $0.5 \mathrm{~h}$ after feeding, whereas increased amino acid levels were observed after $2.5 \mathrm{~h}$. Based on this, the increased IGF-I mRNA levels we observed $1 \mathrm{~h}$ postprandially are likely to be in response to hormonal stimulation. IGF-I regulates many anabolic pathways in skeletal muscle, stimulating cell proliferation and differentiation ${ }^{(39)}$ and myocyte hypertrophy ${ }^{(40)}$ through the subsequent activation of the PI3K/AKT/mTOR pathway and prevention of atrophy mediators ${ }^{(41)}$.

IGF-I exerts its effects on cells through binding to IGF-IR. The expression of IGF-IRa was minimal $12 \mathrm{~h}$ after refeeding, whereas $I G F-I R b$ was not significantly affected by feeding, 
(A)

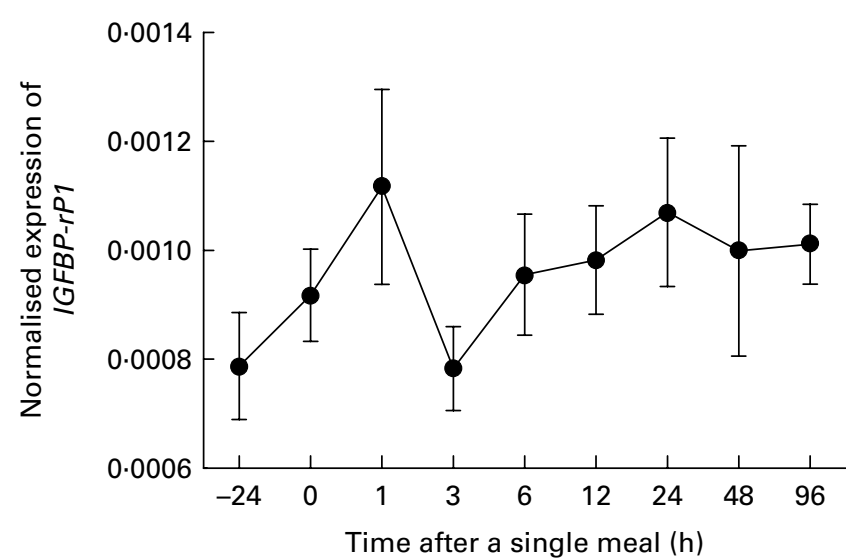

(C)

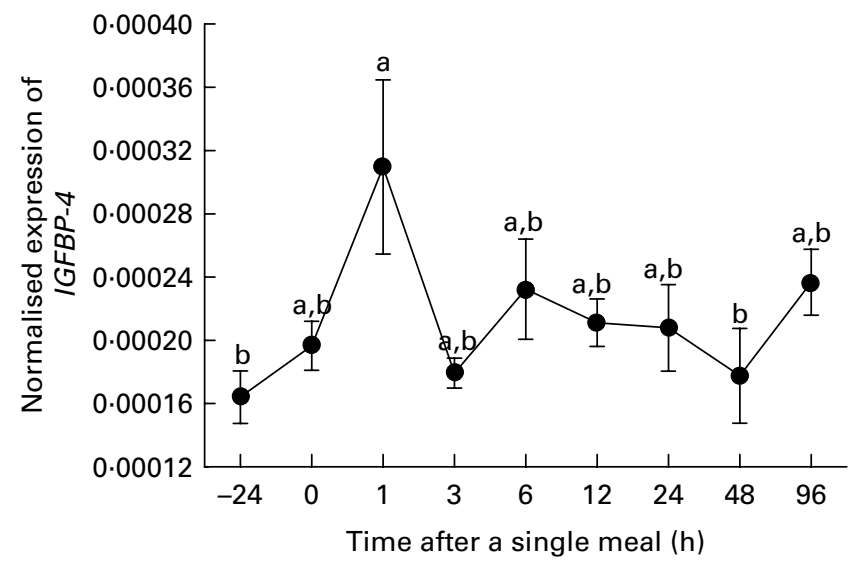

(B)

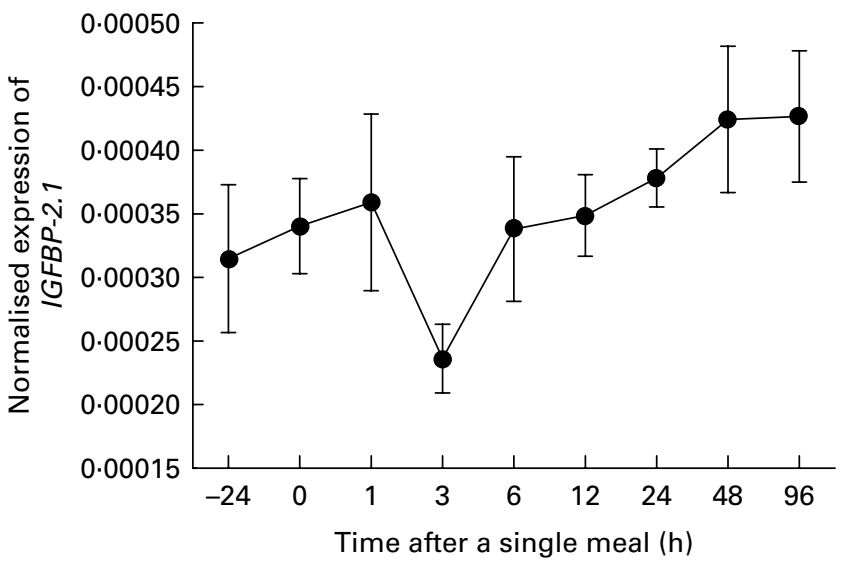

(D)

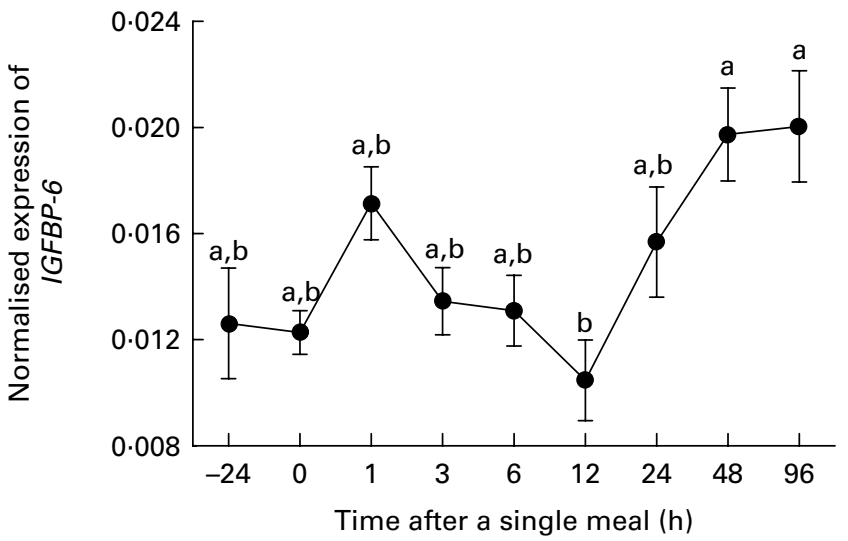

Fig. 3. Expression profiles of insulin-like growth factor binding protein (IGFBP) transcripts (IGFBP-rP1 (A), IGFBP-2.1 (B), IGFBP-4 (C) and IGFBP-6 (D)) in the fast myotomal muscle at different times postprandially. Values are means (seven fish per sample), with their standard errors represented by vertical bars. ${ }^{a, b}$ Mean values with unlike letters were significantly different $(P<0.05)$.

which is consistent with previous results in Atlantic salmon ${ }^{(19)}$. In trout, IGF-IRa was shown to be maximal in fasted fish and declined after refeeding, but no changes were reported in $I G F$ $I R b^{(17)}$. Montserrat et al. ${ }^{(25)}$ pointed towards a different regulation of these two genes by nutritional status, with isoform a responding to refeeding and isoform $b$ responding to fasting. During periods of nutrient restriction, sensitivity to IGF-I seems to be increased in muscle by increasing the abundance of IGF-IRa.

The expression of several IGFBP in response to a single meal followed distinct patterns. IGFBP-rP1, IGFBP-2.1 and $I G F B P-5 \cdot 2$ expression did not vary significantly up to $96 \mathrm{~h}$ after feeding the single meal. Although IGFBP-rP1 did not seem to be modulated by feeding, its expression was positively correlated with that of $I G F-I$, confirming previous results in Atlantic salmon ${ }^{(19)}$ and trout ${ }^{(24)}$. In a previous study with salmon starved for $22 \mathrm{~d}$ and refed to satiation thereafter, $I G F B P-2 \cdot 1$ was significantly down-regulated from $14 \mathrm{~d}$ onwards, which was attributed to an increased availability of IGF-I to the IGF-I receptor ${ }^{(19)}$. IGFBP-4 showed maximal expression $1 \mathrm{~h}$ after feeding and like IGFBP-rP1, was significantly correlated with $I G F-I$ expression, suggesting a coordinated regulation of these genes towards resumption of myogenesis soon after refeeding. IGFBP-6 was significantly correlated with IGF-II, but not with IGF-I. As mammalian IGFBP-6 has a 10- to 100-fold higher affinity for IGF-II than $\mathrm{IGF}^{(42)}$, the present results suggest a role for Atlantic salmon IGFBP-6 in IGF-II regulation. Amaral \& Johnston ${ }^{(38)}$ pointed to lineage-specific differences in IFGBP function and regulation among teleosts, suggested by the apparent lack of IGFBP-4 in zebrafish, so caution is needed when comparing results between different fish species.

The role of IGF-II in fish metabolism is unclear, but it seems to be implicated in the autocrine/paracrine regulation of growth $^{(23,25)}$. In the present study, IGF-II mRNA expression showed a dramatic decrease in muscle of refed salmon until $6 \mathrm{~h}$ after feeding, but levels were restored $12 \mathrm{~h}$ postprandially. Likewise, Bower et $a{ }^{(19)}$ reported a significant decrease of $I G F-I I$ expression in a time-dependent fashion after at least $7 \mathrm{~d}$ continuous feeding. Hevrøy et al. ${ }^{(43)}$ reported an upregulation of $I G F-I I$ in the muscle of fish fed high lysine levels, suggesting a role as an anabolic stimulatory agent. In juvenile rainbow trout, IGF-II mRNA levels in myotomal muscle tissue increased $34 \mathrm{~d}$ after refeeding ${ }^{(17)}$, but in a 
(A)

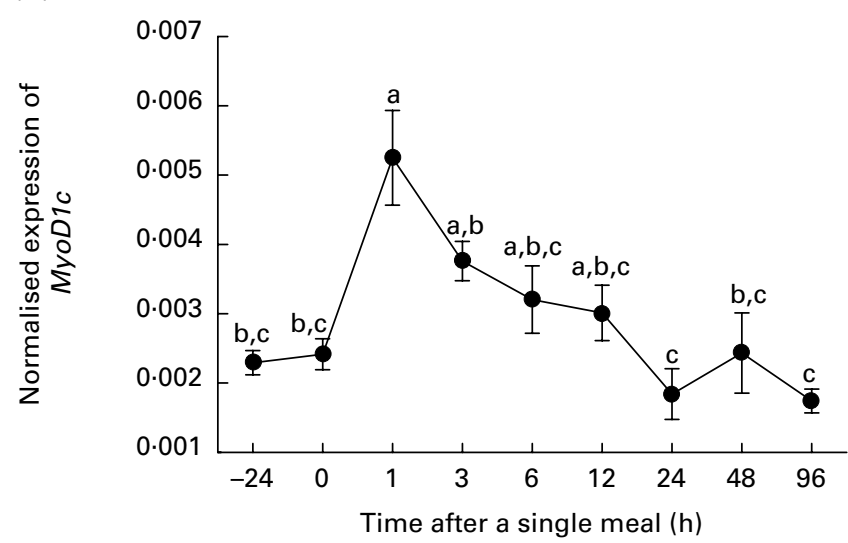

(C)

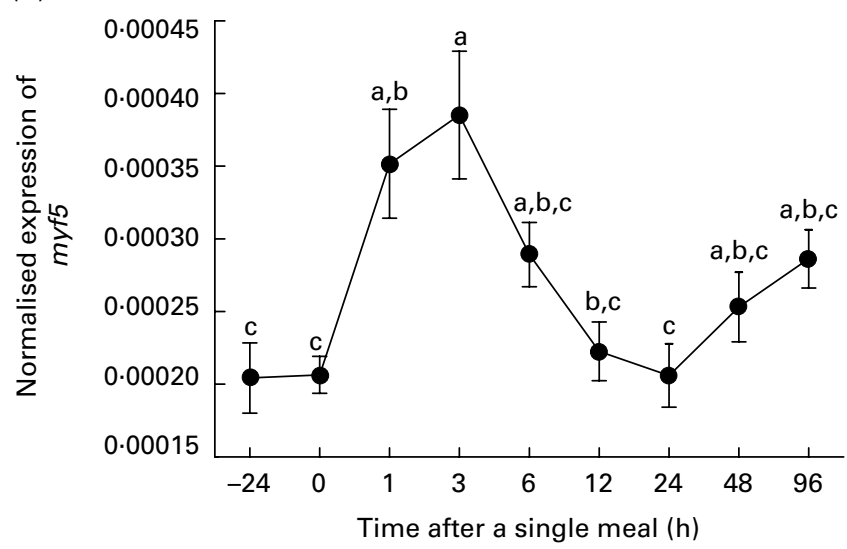

(E)

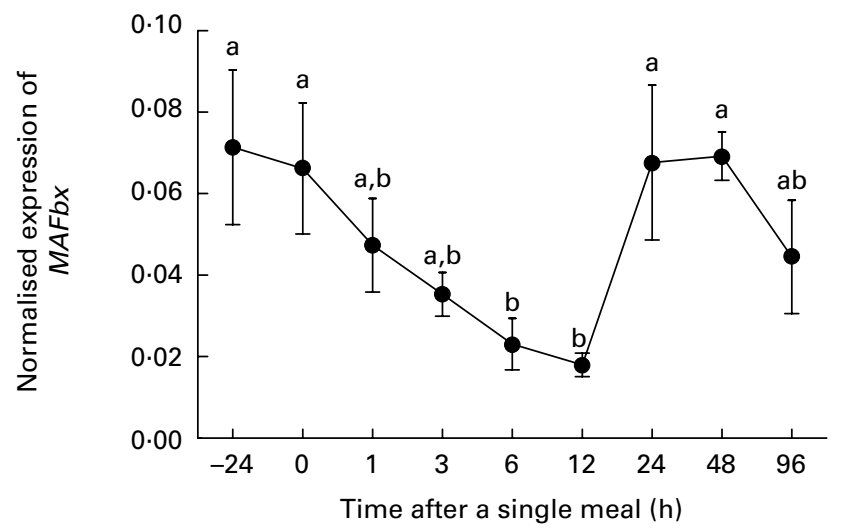

(B)

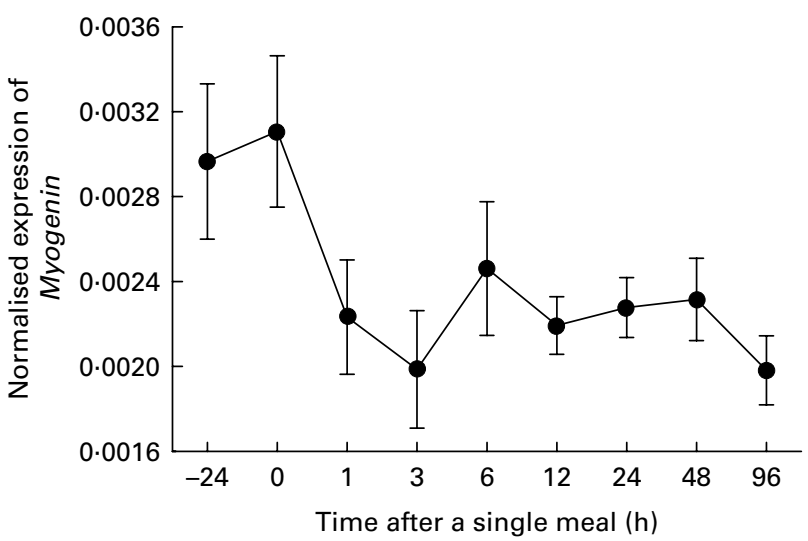

(D)

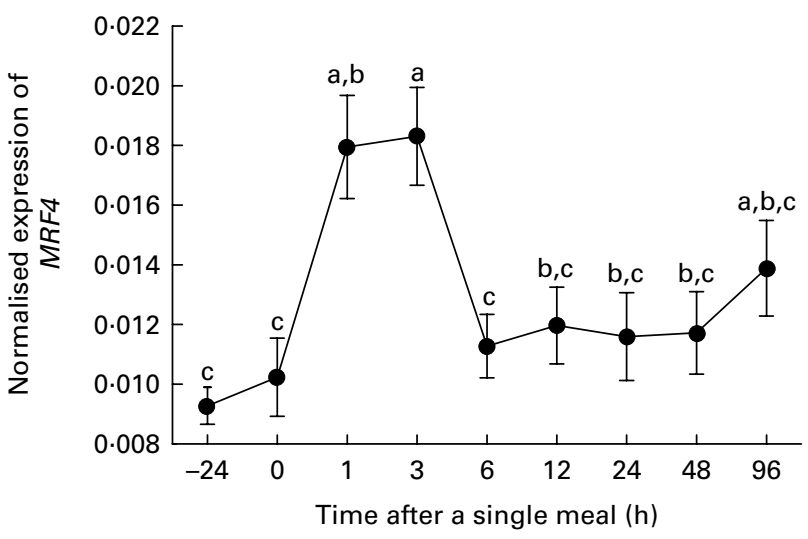

(F)

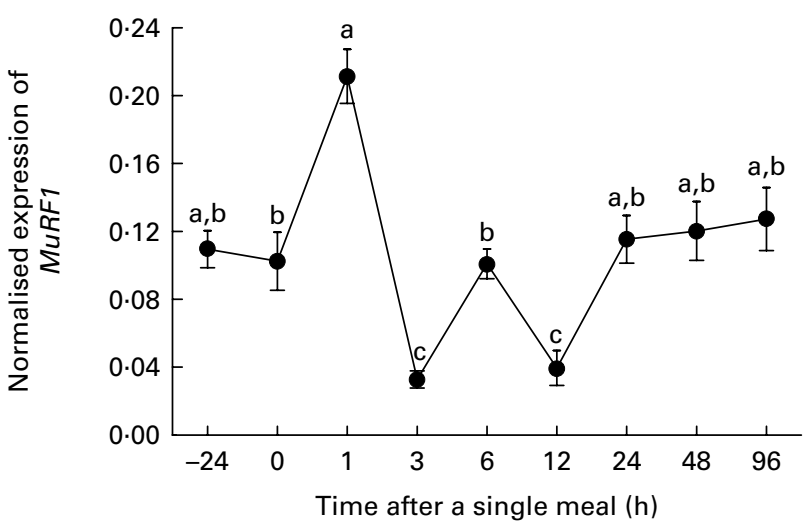

Fig. 4. Normalised expression of muscle-regulatory factors (MRF) (MyoD1c (A), Myogenin (B), myogenic factor 5 (myf5) (C) and MRF4 (D)) and the atrophy genes (MAFbx/atrogin-1 $(\mathrm{E})$ and muscle RING finger protein $1(M u R F 1)(F)$ ) at different times postprandially. Values are means (seven fish per sample), with their standard errors represented by vertical bars. ${ }^{a, b, c}$ Mean values with unlike letters were significantly different $(P<0.05)$.

different study Montserrat et $a l^{(25)}$ could not observe any effect of fasting or refeeding on IGF-II mRNA expression. These distinct responses could be due to distinct developmental stages and/or nutritional status of the fish.

The expression of several MRF has been reported to be modulated by the nutritional status of the fish. The three paralogues of MyoD1 responded differently to the meal distribution. MyoD1a showed no variation following the meal, whereas MyoD1b and MyoD1c peaked $1 \mathrm{~h}$ after feeding a single meal. The up-regulation of $M y o D 1 c$ following the single meal was positively correlated with IGF-I. No clear change in either MyoD isoform could be observed during compensatory growth in trout ${ }^{(25)}$, but amino acid withdrawal led to a down-regulation of both $M y o D 1 b$ and MyoD1c in salmon myogenic cells culture, and increased levels of Pax 7 mRNA, suggesting that serum and amino acid withdrawal 


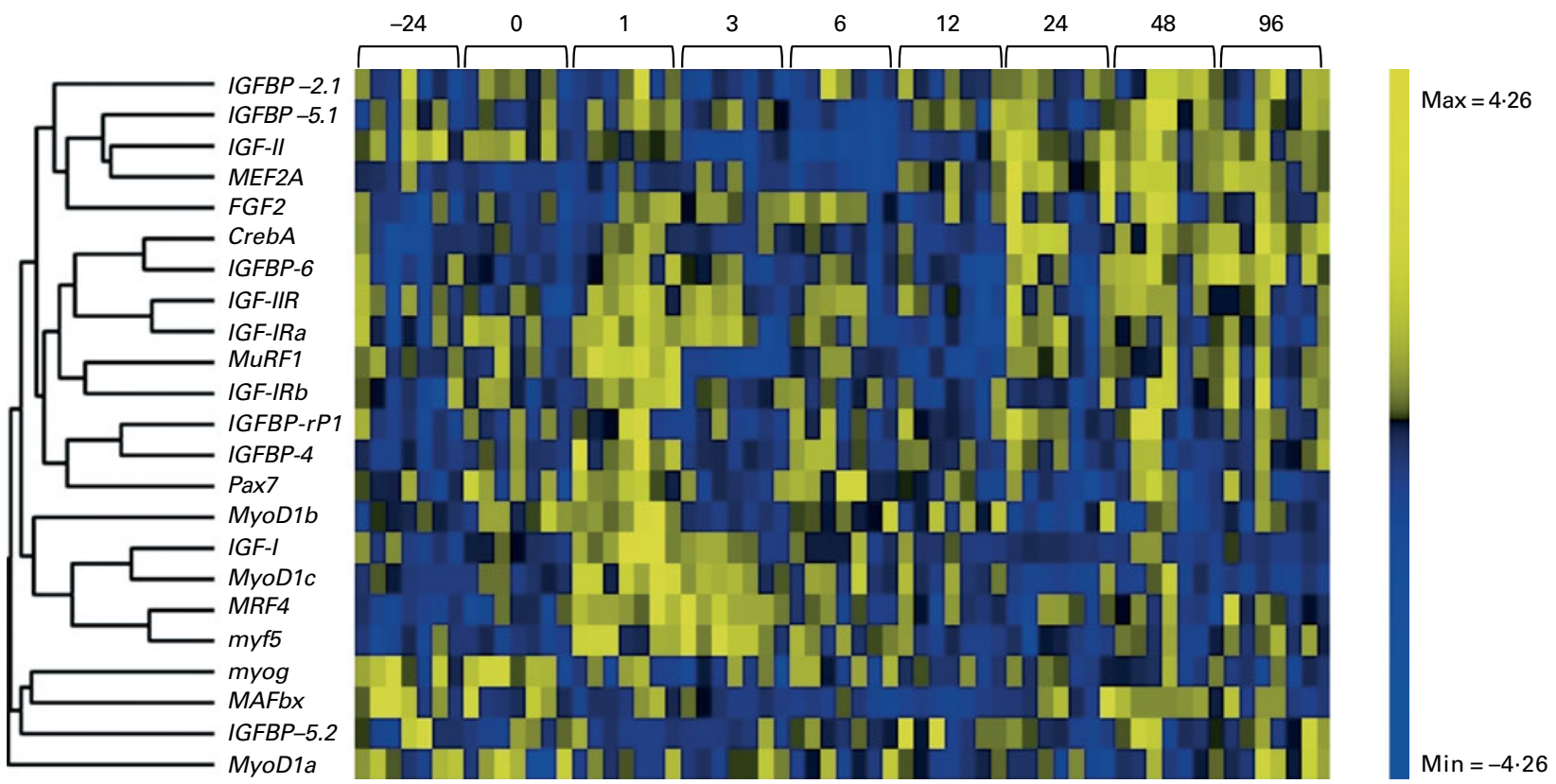

Fig. 5. Heat map summary and unsupervised hierarchical clustering analysis of the genes in muscle according to the similarity in their expression across different postprandial times ( -24 to $96 \mathrm{~h}$ ). Yellow and blue shading represents the maximal (Max) and lowest (Min) transcript abundance, respectively. IGFBP-2.1, insulinlike growth factor binding protein 2 paralogue 1; IGFBP-5.1, insulin-like growth factor binding protein 5 paralogue 1; IGF-II, insulin-like growth factor II; MEF2A, myocyte enhancer factor 2A; FGF2, fibroblast growth factor 2; CrebA, cyclic AMP response element binding protein; IGFBP-6, insulin-like growth factor binding protein 6; IGF-IIR, insulin-like growth factor II receptor; IGF-IRa, insulin-like growth factor I receptor a; MuRF1, muscle RING finger protein 1; IGF-IRb, insulin-like growth factor I receptor b; IGFBP-rP1, insulin-like growth factor binding protein-related protein 1; IGFBP-4, insulin-like growth factor binding protein 4; Pax7, paired box protein 7; MyoD1b, myoblast determination factor 1b; IGF-I, insulin-like growth factor I; MyoD1c, myoblast determination factor 1c; MRF4, myogenic factor 6; myf5, myogenic factor 5; myog, myogenin; MAFbx, muscle atrophy F box; IGFBP-5.2, insulin-like growth factor binding protein 2 paralogue 2; MyoD1a, myoblast determination factor $1 \mathrm{a}$

leads to cell cycle arrest and the production of quiescent cells $^{(44)}$

MRF4 and myf5 showed a dramatic and simultaneous upregulation immediately after feeding a single meal. MRF4 and $m y f 5$ are closely linked genes that clustered together (Fig. 5). Myf5 is the first MRF to be expressed during embryonic development and is considered a specification factor that determines the muscular lineage, whereas MRF4 functions later and can be considered as both a specification and a differentiation factor $^{(45)}$. An early peak in $m y f 5$ expression was correlated with increased $M y O D 1 b$ transcript abundance during the maturation of an Atlantic salmon primary myogenic cell culture $^{(44)}$, and so it is interesting that we see $m y f 5$ and MyoD1b clustering together (Fig. 5). To our knowledge there are few studies reporting the nutritional modulation of myf5 and MRF4 in fish, but the present results point towards a possible nutritional regulation of muscle fibre number. Lower growth due to high dietary lipid levels in Senegalese sole was associated with reduced expression of muscle MRF4, but not myf5 (46)

In the present study no modulation of Pax7 or FGF2 was observed in refeeding, although Chauvigné et al. ${ }^{(17)}$ indicated FGF2 was a critical modulator of trout myotomal muscle growth $4 \mathrm{~d}$ after refeeding. Expression of the muscle-specific gene Myogenin decreased soon after a single meal but without statistical significance $(P>0 \cdot 05)$. Similarly, Bower et al. ${ }^{(19)}$ described a Myogenin reduction in response to feeding. In rainbow trout, Myogenin mRNA was unchanged $4 \mathrm{~d}$ after refeeding, but increased significantly after $12 \mathrm{~d}^{(17)}$. However, increased Myogenin expression was reported in trout during feed restriction, suggesting a role in muscle maintenance ${ }^{(25)}$.

The genes regulated by atrophy include the $\mathrm{E} 3$ ubiquitin ligase MAFbx/atrogin-1 and MuRF1 that are up-regulated during catabolism and atrophy and down-regulated during fibre hypertrophy. Fasted individuals showed increased expression of MAFbx/atrogin-1 and MuRF1 and both genes were strongly down-regulated after feeding in Atlantic salmon $^{(14,47)}$ and zebrafish ${ }^{(38)}$. The present results showed that a single meal was capable of promoting $M A F b x /$ atrogin-1 depression, though its effect on MuRF1 was less clear. The increased expression observed $1 \mathrm{~h}$ postprandially for $M u R F 1$ at first glance is puzzling. However, it is noteworthy that during the fasting period, fish were inactive, but became active once feed was distributed in the tank. This sudden increase in activity could lead to depletions in muscle glucose reserves, leading to metabolic stress in the muscle, and MuRF1 is known to regulate responses to metabolic stress in muscle of mice ${ }^{(48)}$. MAFbx/atrogin-1 is regulated by both IGF signalling and amino acid availability ${ }^{(47)}$, and the expression patterns we observed following a single meal is consistent with this. In trout, circulating amino acids remained high from 2.5 to $12 \mathrm{~h}$ following feeding and returned to those of a fasted state by $24 \mathrm{~h}^{(21)}$ and the expression profile we observed for MAFbx/atrogin-1 is inversely proportional to this The decrease in MAFbx/atrogin-1 expression (within $1 \mathrm{~h}$ ) suggests that hormonal stimulation of the AKT/mTOR pathway 
via endocrine signalling or through local production of IGF-I is responsible for this rapid transcriptional response that could result in increased protein synthesis. Recent findings demonstrated that $M A F b x /$ atrogin-1 contributed to muscle wasting by down-regulating protein synthesis whereas MuRF1 is mostly involved in the breakdown of myofibrillar proteins ${ }^{(49)}$.

In conclusion, the present results show that the transcription of several growth-related genes in the fast skeletal muscle of Atlantic salmon responds quickly to a single meal. In muscle, our observations indicate that refeeding induced a coordinated regulation of several genes involved in a strong resumption of myogenesis with feeding. IGF-I, MyoD1c, MRF4 and myf5 transcripts in muscle were sharply up-regulated in response to refeeding, being promising candidate genes involved in a cellular-level signalling system that regulates fish myotomal muscle growth. It is also suggested that local production of IGF-I within the muscle might suppress catabolic pathways depressing MAFbx/atrogin-1.

\section{Acknowledgements}

We thank Dr Vera Vieira-Johnston, Attia Anwar and Cristina Salmeron for their assistance in the sampling and laboratorial analysis. L. M. P. V. carried out the main experimental work and wrote the draft under the direction of the project designer and leader I. A. J.; N. I. B. assisted with the experimental design, the laboratory work and draft writing. L. M. P. V. was supported by a Foundation for Science and Technology (FCT) grant during the sabbatical licence in St Andrews. The present study was supported by Biotechnology and Biological Research Council grant no. BB/D015391/1. There are no conflicts of interest.

\section{References}

1. Jobling M (1994) Fish Bioenergetics, 1st ed. London: Chapman \& Hall.

2. Nicieza AG \& Metcalfe NB (1997) Growth compensation in juvenile Atlantic salmon: responses to depressed temperature and food availability. Ecology 78, 2385-2400.

3. Peragón J, Barroso JB, García-Salguero L, et al. (1999) Selective changes in the protein-turnover rates and nature of growth induced in trout liver by long-term starvation followed by re-feeding. Mol Cell Biochem 201, 1-10.

4. Maclean A \& Metcalfe NB (2001) Social status, access to food, and compensatory growth in juvenile Atlantic salmon. J Fish Biol 58, 1331-1346.

5. Ali M, Nicieza A \& Wootton RJ (2003) Compensatory growth in fishes: a response to growth depression. Fish Fish 4 , 147-190.

6. Ballantyne JS (2001) Amino acid metabolism. In Fish Physiology, pp. 77-107 [PA Wright and PM Anderson, editors]. London: Academic Press.

7. Carter C, Houlihan D, Kiessling A, et al. (2007) Physiological effects of feeding. In Food Intake in Fish, pp. 297-331 [D Houlihan, $\mathrm{T}$ Boujard and $\mathrm{M}$ Jobling, editors]. Oxford: Blackwell Science Ltd.

8. Kaput J, Klein KG, Reyes EJ, et al. (2004) Identification of genes contributing to the obese yellow Avy phenotype: caloric restriction, genotype, diet $\times$ genotype interactions. Physiol Genomics 18, 316-324.
9. Kaput J \& Rodriguez RL (2004) Nutritional genomics: the next frontier in the postgenomic era. Physiol Genomics 16, $166-177$.

10. Kimball SR \& Jefferson LS (2004) Regulation of global and specific mRNA translation by oral administration of branched-chain amino acids. Biochem Biophys Res Commun 313, 423-427.

11. Hornick JL, Van Eenaeme C, Gérard O, et al. (2000) Mechanisms of reduced and compensatory growth. Domest Anim Endocrinol 19, 121-132.

12. Bower NI \& Johnston IA (2010) Discovery and characterization of nutritionally regulated genes associated with muscle growth in Atlantic salmon. Physiol Genomics $42 \mathrm{~A}$ 114-130.

13. Panserat S \& Kaushik SJ (2010) Regulation of gene expression by nutritional factors in fish. Aquacult Res $\mathbf{4 1}$, $751-762$.

14. Bower NI, Taylor RG \& Johnston IA (2009) Phasing of muscle gene expression with fasting-induced recovery growth in Atlantic salmon. Front Zool 6, 18-30.

15. Rescan PY, Montfort J, Ralliere C, et al. (2007) Dynamic gene expression in fish muscle during recovery growth induced by a fasting-refeeding schedule. BMC Genomics $\mathbf{8}, 438-455$.

16. Duan C (1998) Nutritional and developmental regulation of insulin-like growth factors in fish. J Nutr 128, 306S-314S.

17. Chauvigné F, Gabillard JC, Weil C, et al. (2003) Effect of refeeding on IGFI, IGFII, IGF receptors, FGF2, FGF6, and myostatin mRNA expression in rainbow trout myotomal muscle. Gen Comp Endocrinol 132, 209-215.

18. Reinecke M, Bjornsson BT, Dickhoff WW, et al. (2005) Growth hormone and insulin-like growth factors in fish: where we are and where to go. Gen Comp Endocrinol 142, 20-24.

19. Bower NI, Li XJ, Taylor R, et al. (2008) Switching to fast growth: the insulin-like growth factor (IGF) system in skeletal muscle of Atlantic salmon. J Exp Biol 211, 3859-3870.

20. Montserrat N, Sánchez-Gurmaches J, García de la Serrana D, et al. (2007) IGF-I binding and receptor signal transduction in primary cell culture of muscle cells of gilthead sea bream: changes throughout in vitro development. Cell Tissue Res 330, 503-513.

21. Seiliez I, Gabillard JC, Skiba-Cassy S, et al. (2008) An in vivo and in vitro assessment of TOR signaling cascade in rainbow trout (Oncorbynchus mykiss). Am J Physiol Regul Integr Comp Physiol 295, R329-R335.

22. Erbay E, Park I-H, Nuzzi PD, et al. (2003) IGF-II transcription in skeletal myogenesis is controlled by mTOR and nutrients. J Cell Biol 163, 931-936.

23. Codina M, García de la Serrana D, Sánchez-Gurmaches J, et al. (2008) Metabolic and mitogenic effects of IGF-II in rainbow trout (Oncorbynchus mykiss) myocytes in culture and the role of IGF-II in the PI3K/Akt and MAPK signalling pathways. Gen Comp Endocrinol 157, 116-124.

24. Gabillard J-C, Kamangar BB \& Montserrat N (2006) Coordinated regulation of the GH/IGF system genes during refeeding in rainbow trout (Oncorbynchus mykiss). J Endocrinol 191, $15-24$

25. Montserrat N, Gabillard JC, Capilla E, et al. (2007) Role of insulin, insulin-like growth factors, and muscle regulatory factors in the compensatory growth of the trout (Oncorbynchus mykiss). Gen Comp Endocrinol 150, 462-472.

26. Glass DJ (2005) Skeletal muscle hypertrophy and atrophy signaling pathways. Int J Biochem Cell Biol 37, 1974-1984.

27. Cleveland BM \& Weber GM (2010) Effects of insulin-like growth factor-I, insulin, and leucine on protein turnover 
and ubiquitin ligase expression in rainbow trout primary myocytes. Am J Physiol 298, R341-R350.

28. Terova G, Rimoldi S, Chini V, et al. (2007) Cloning and expression analysis of insulin-like growth factor I and II in liver and muscle of sea bass (Dicentrarchus labrax, L.) during long-term fasting and refeeding. J Fish Biol 70, 219-233.

29. Hagen O, Fernandes JMO, Solberg C, et al. (2009) Expression of growth-related genes in muscle during fasting and refeeding of juvenile Atlantic halibut, Hippoglossus hippoglossus L. Comp Biochem Physiol B-Biochem Mol Biol 152, 47-53.

30. Bustin SA, Benes V, Garson JA, et al. (2009) The MIQE Guidelines: minimum information for publication of quantitative real-time PCR experiments. Clin Chem 55, 611-622.

31. Ruijter JM, Ramakers C, Hoogaars WMH, et al. (2009) Amplification efficiency: linking baseline and bias in the analysis of quantitative PCR data. Nucleic Acids Res 37, e45.

32. Vandesompele J, De Preter K, Pattyn F, et al. (2002) Accurate normalization of real-time quantitative RT-PCR data by geometric averaging of multiple internal control genes. Genome Biol 3, research0034.1-research0034.11.

33. Muller PY, Janovjak H, Miserez AR, et al. (2002) Processing of gene expression data generated by quantitative real-time RT-PCR. Biotechniques 32, 1372-1378.

34. de Hoon MJL, Imoto S, Nolan J, et al. (2004) Open source clustering software. Bioinformatics 20, 1453-1454.

35. Rehfeldt C, Te Pas MFW, Wimmers K, et al. (2011) Advances in research on the prenatal development of skeletal muscle in animals in relation to the quality of muscle-based food. II - Genetic factors related to animal performance and advances in methodology. Animal 5, 718-730.

36. Duan C \& Plisetskaya EM (1993) Nutritional regulation of insulin-like growth factor-I mRNA expression in salmon tissues. J Endocrinol 139, 243-252.

37. Montserrat N, Gomez-Requeni P, Bellini G, et al. (2007) Distinct role of insulin and IGF-I and its receptors in white skeletal muscle during the compensatory growth of gilthead sea bream (Sparus aurata). Aquaculture 267, 188-198.

38. Amaral IPG \& Johnston IA (2011) Insulin-like growth factor (IGF) signalling and genome-wide transcriptional regulation in fast muscle of zebrafish following a single-satiating meal. J Exp Biol 214, 2125-2139.

39. Castillo J, Codina M, Martinez ML, et al. (2004) Metabolic and mitogenic effects of IGF-I and insulin on muscle cells of rainbow trout. Am J Physiol Regul Integr Comp Physiol 286 R935-R941.

40. Florini JR, Ewton DZ \& Coolican SA (1996) Growth hormone and the insulin-like growth factor system in myogenesis. Endocr Rev 17, 481-517.

41. Stitt TN, Drujan D, Clarke BA, et al. (2004) The IGF-1/PI3K/ Akt pathway prevents expression of muscle atrophy-induced ubiquitin ligases by inhibiting FOXO transcription factors. Mol Cell 14, 395-403.

42. Bach LA (2005) IGFBP-6 five years on; not so 'forgotten'? Growth Horm IGF Res 15, 185-192.

43. Hevrøy EM, El-Mowafi A, Taylor RG, et al. (2007) Lysine intake affects gene expression of anabolic hormones in Atlantic salmon, Salmo salar. Gen Comp Endocrinol 152, $39-46$.

44. Bower NI \& Johnston IA (2010) Paralogues of Atlantic salmon myoblast determination factor genes are distinctly regulated in proliferating and differentiating myogenic cells. Am J Physiol Regul Integr Comp Physiol 298, R1615-R1626.

45. Chen YH \& Tsai HJ (2008) Myogenic regulatory factors Myf5 and Mrf 4 of fish: current status and perspective. J Fish Biol 73, 1872-1890.

46. Campos C, Valente LMP, Borges P, et al. (2010) Dietary lipid levels have a remarkable impact on the expression of growth-related genes in Senegalese sole (Solea senegalensis Kaup). J Exp Biol 213, 200-209.

47. Bower NI, de la serrana DG \& Johnston IA (2010) Characterisation and differential regulation of MAFbx/Atrogin- $1 \alpha$ and $\beta$ transcripts in skeletal muscle of Atlantic salmon (Salmo salar). Biochem Biophys Res Commun 396, 265-271.

48. Hirner S, Krohne C, Schuster A, et al. (2008) MuRF1-dependent regulation of systemic carbohydrate metabolism as revealed from transgenic mouse studies. J Mol Biol 379, 666-677.

49. Attaix D \& Baracos VE (2010) MAFbx/Atrogin-1 expression is a poor index of muscle proteolysis. Curr Opin Clin Nutr Metab Care 13, 223-224. 